\title{
Antimicrobial activities of citronella (Cymbopogon nardus) essential oil against several oral pathogens and its volatile compounds
}

\author{
Henny Zaliyana Ahmad Kamal ${ }^{1}$, Tuan Nadrah Naim Tuan Ismail'2, Erry Mochamad \\ Arief $^{3^{*}}$, Kannan Thirumulu Ponnuraj ${ }^{4}$ \\ ${ }^{1}$ Balok Dental Clinic, Ministry of Health of Malaysia, Malaysia \\ 2Department of Pharmacology, School of Dental Sciences Universiti Sains Malaysia, Malaysia \\ ${ }^{3}$ Department of Periodontology, School of Dental Sciences Universiti Sains Malaysia, Malaysia \\ ${ }^{4}$ Genome Centre, School of Dental Sciences Universiti Sains Malaysia, Malaysia
}

\begin{abstract}
Introduction: Cymbopogon nardus is a strong aromatic plant with relevant medicinal properties due to its essential chemical compounds and its potential therapeutic effects. This study was aimed to evaluate the antimicrobial activities of citronella essential oil against several oral pathogens and to identify the volatile compounds. Methods: The essential oil of $C$. nardus was purchased from Excellent Wisdom Sdn. Bhd., Malaysia. The source of raw material was collected from Malacca, the southern region of Malaysia, and the company made its taxonomic identification. An experimental in-vitro study was conducted on the essential oil processed from C. nardus genus Cymbopogon of Poaceae family. The in-vitro antimicrobial activities of $C$. nardus essential oil were evaluated against Streptococcus mutans (ATCC 25175), Streptococcus sobrinus (ATCC 33478), and Candida albicans (ATCC 10231) using agar well diffusion assay. The identification of the volatile compounds was performed using gas chromatographymass spectrometry (GC-MS). Results: The $C$. nardus essential oil exhibited inhibitory activity against C. albicans at the concentration of $6.25 \%$, whereby the inhibitory activity against S. mutans and S. sobrinus began at the concentration of $25 \%$. The antimicrobial activity of $C$. nardus essential oil was statistically significant at the concentration of $50 \%$ in all tested pathogens. The GC-MS analysis of the $C$. nardus essential oil revealed the presence of few constituents, which include monoterpenes, diterpenes, sesquiterpenes and phenolic compounds. Monoterpenes were the major identified terpenoids and contributed to $54.45 \%$ of the total volatile composition. The main identified monoterpenes were citronellal (11.35\%), z-Citral (11.34\%), B-Myrcene (6.70\%), and B-Trans-ocimene $(6.03 \%)$, which was the first time B-Myrcene and B-Trans-ocimene was found in high percentage. Conclusion: $C$. nardus essential oil is an active antibacterial agent against several oral pathogens, and the percentages of active volatile compounds are different within different origins.
\end{abstract}

Keywords: Antimicrobial, Cymbopogon nardus, essential oil, GC-MS, oral pathogens.

p-ISSN: 1979-0201; e-ISSN: 2549-6212; Available from: http://jurnal.unpad.ac.id/pjd/article/view/24966

DOI: $10.24198 /$ pjd.vol32no1.24966

Submission: Dec 04, 2019; Accepted: Mar 3, 2020; Published online: Mar 31, 2020

"Corresponding author: Erry Mochamad Arief, Department of Periodontology, School of Dental Sciences Universiti Sains Malaysia, Malaysia. 16150 Kubang Kerian, Kelantan, Malaysia; Phone: +60133269785; Email: erry@usm.my 


\section{INTRODUCTION}

Cymbopogon nardus (C. nardus), commonly known as citronella grass, is a perennial grass of the Poaceae grass family. It is a tall herb and can grow up to 1 to $1.5 \mathrm{~m}$. In Malaysia is called as "Serai wangi" due to its aroma which is stronger than the lemongrass. C. nardus is distributed throughout the tropical region of Asia such as India, Burma, Malaysia Peninsular, Sri Lanka, and Indonesia.

It is a rugged plant and able to adapt to different types of soil and climate. In Malaysia, it is usually planted at the house backyard, and since the past ten years, it has been cultivated in large quantities in Malaysia for extracting the valuable essential oil.

C. nardus is traditionally used as a mosquito repellent, household fumigant, and as a fragrance of cosmetics. The properties of $C$. nardus have been extensively investigated and showed a varied range of antimicrobial effects including antibacterial, antifungal, and antiparasitic properties. ${ }^{1-3}$ However, its antimicrobial activity against oral pathogens remains unknown. Despite the commonly used of standard antibacterial agents including $0.2 \%$ chlorhexidine and triclosan in oral care products, finding an alternative natural source antibacterial agent is a top priority because adverse effects such as emerging multidrugresistant pathogens in the environment by the latter. ${ }^{4}$ Microbes such as Streptococcus mutans and Streptococcus sobrinus are endogenous bacteria in pathogenesis of dental caries. While Candida albicans have been implicated in oral diseases as the most common opportunistic oral fungus. 5,6

Therefore, the present study was aimed to investigate the antimicrobial effects of the C. nardus essential oils against S. mutans, S. sobrinus and C. albicans and identified of its volatile components were investigated using agar well diffusion method and gas chromatographymass spectrometry (GC-MS).

\section{METHODS}

This study was an experimental and in-vitro study of antimicrobial properties of the commercialised C. nardus essential oil. The extract was chosen due to its abundance of resource locally and recent enthusiasm in natural products and medicinal plants for its biological activities and therapeutic potential.

\section{Sample of C. nardus essential oil}

Sample of $C$. nardus essential oil was purchased from Excellent Wisdom Sdn. Bhd., Malacca, Malaysia. The raw materials were extracted from C. nardus genus Cymbopogon of Poaceae family, which were commercially cultivated in the same region of Malacca, Malaysia.

\section{Organism testing}

In the current study, the microorganisms S. mutans (ATCC 25175), S. sobrinus (ATCC 33478) and C. albicans (ATCC 10231) were obtained from the Craniofacial Laboratory, School of Dental Sciences, Universiti Sains Malaysia, Kelantan, Malaysia. The media used in this study were purchased from Oxoid Ltd., UK.

\section{Determination of antimicrobial activity}

C. nardus essential oil was tested for antimicrobial activity at different concentration (50, 25, 12.5 and $6.25 \%$ ) using agar well diffusion method. This method will determine the ability of $C$. nardus essential oil at a different concentration to inhibit the formation of new bacterial and fungal colonies through the formation of an inhibition zone. Each bacterium was suspended in $2 \mathrm{ml}$ of peptone water whereas $C$. albicans was suspended in $2 \mathrm{ml}$ of sterile saline. The turbidity of this suspension was adjusted to a $0.5 \mathrm{Mc}$ Farland standard by using turbidimeter. A sterile cotton swab was dipped into the inoculum suspension, and a lawn was made on Mueller-Hinton agar (S. sobrinus), Mueller-Hinton blood agar (S. mutans) and Sabouraud dextrose agar (C. albicans) plates. The sterile well was impregnated with $100 \mu \mathrm{l}$ of $C$. nardus essential oil at different concentration. Well infused with $100 \mu \mathrm{l}$ chlorhexidine $0.2 \%$ and dimethyl sulfoxide (DMSO) were used as positive and negative controls, respectively. These plates were then incubated at $37^{\circ} \mathrm{C}$ for 24 to $48 \mathrm{~h}$, and the zone of inhibition was measured. This experiment was performed in triplicates. Diameter of the inhibition zone (the clear area around each well) was measured with a digital calliper in millimetres. Data collection was conducted on each plate after 24 to $48 \mathrm{~h}$. 
Gas Chromatography Mass Spectrometry (GCMS) analysis

The GC-MS analysis of $C$. nardus essential oil was performed by GC-MS (Hewlett Packard 6890 Gas Chromatograph with 5973N Mass Selective Detector). The column was fused silica capillary, HP-5 column $(30 \mathrm{~m} \times 0.25 \mathrm{~mm}$ i.d $\times 0.25 \mu \mathrm{m}$ film thickness) (Agilent Technologies, USA). The carrier gas was helium at the flow rate of $1.0 \mathrm{ml} /$ min. The column temperature was maintained at $50 \mathrm{~W}^{\circ} \mathrm{C}$ for $2 \mathrm{~min}$, then programmed at $20^{\circ} \mathrm{C} / \mathrm{min}$ to $280^{\circ} \mathrm{C}$ and waited for $10 \mathrm{~min}$. The injection and interface temperatures were set at $250^{\circ} \mathrm{C}$ and $280^{\circ} \mathrm{C}$, respectively. One $\mu \mathrm{l}$ sample was injected in splitless mode and analysed in MS full scan mode ( $\mathrm{m} / \mathrm{z}$ 40-650). The electron ionization was fixed at $70 \mathrm{eV}$. The solvent delay was $4 \mathrm{~min}$. Acquisition of data was performed using Chemsation software. The identification of the peaks was based on computer matching of the mass spectra with the National Institute of Standards and Technology (NIST02) and Wiley 275 libraries ( $\geq 80 \%$ matching). The percentage compound was calculated from the summation of the peak areas of $C$. nardus compounds.

\section{Statistical analysis}

Results were expressed as Mean \pm SD for illustration. Statistical analysis was performed using a statistical package, SPSS Statistics Campus Edition version 24.0 by applying values to determine the effect between different concentrations of C.nardus essential oil against tested microorganisms.

\section{Statement of human and animal rights}

This study did not involve human or animal subjects performed by any of the researchers.

\section{RESULTS}

The antimicrobial study of $C$. nardus essential oil exhibited antibacterial and antifungal properties against all tested microorganisms at a concentration of at least $25 \%$, as shown in Table 1. The $C$. albicans were the most sensitive to the $C$. nardus essential oil at the concentration of $6.25 \%$, whereby $\mathrm{S}$. mutans and $\mathrm{S}$. sobrinus were sensitive to the $C$. nardus essential oil at the concentration of $25 \%$. These results showed that the antimicrobial activities of the $C$. nardus essential oil varies with different concentrations. At the concentration of 25 and $50 \%$, there is an antimicrobial activity of the essential oil towards all the tested pathogens. Results of the GC-MS analysis of C. nardus essential oil cultivated in Malacca, Malaysia, are shown in Table 2. A total of 35 volatile compounds were identified, including 13 monoterpenes, 2 diterpenes, 9 sesquiterpenes, 2 phenolic compounds, and 9 others. Monoterpenes were the dominant class in the $C$. nardus essential oil, and they accounted for $54.45 \%$ of the total volatile composition. The main identified monoterpene was citronellal $(11.35 \%)$, followed by $z$-Citral

Table 1. Antimicrobial activity of C.nardus essential oil

\begin{tabular}{|c|c|c|c|c|c|c|c|c|c|c|}
\hline \multirow{4}{*}{ Tested microorganism } & \multicolumn{10}{|c|}{ Inhibition zone diameter $(\mathrm{mm})$} \\
\hline & \multicolumn{8}{|c|}{ C. nardus essential oil concentration } & \multirow{2}{*}{\multicolumn{2}{|c|}{$\begin{array}{c}\text { Chlorhexidine concentration } \\
0.2 \%\end{array}$}} \\
\hline & \multicolumn{2}{|c|}{$6.25 \%$} & \multicolumn{2}{|c|}{$12.5 \%$} & \multicolumn{2}{|c|}{$25 \%$} & \multicolumn{2}{|c|}{$50 \%$} & & \\
\hline & Mean & SD & Mean & SD & Mean & SD & Mean & SD & Mean & SD \\
\hline S. sobrinus & & & & & 19.34 & 0.85 & 42.20 & 2.82 & 29.39 & 0.46 \\
\hline S. mutans & & & & & 23.56 & 2.92 & 32.83 & 2.52 & 27.52 & 0.08 \\
\hline C. Albicans & 22.80 & 0.57 & 22.83 & 0.44 & 26.02 & 0.24 & 26.70 & 0.50 & 23.84 & 0.26 \\
\hline
\end{tabular}

*The experiments were performed in triplicate and the results are presented in the median values, with $0.2 \%$ chlorhexidine used as positive $(+)$ control 
(11.34\%), B-Myrcene $(6.70 \%)$, B-Trans-ocimene (6.03\%), geranyl acetate (3.82\%), limonene (3.50\%), and citronellol (3.22\%).

After monoterpenes, sesquiterpenes were the dominant constituent in the citronella oil with a total percentage of $5.20 \%$. Nine sesquiterpenes

Table 2. Volatile compounds of $C$. nardus essential oil

\begin{tabular}{|c|c|}
\hline Compounds & Composition (\%) \\
\hline \multicolumn{2}{|l|}{ Monoterpenes } \\
\hline 1R-a-Pinene & $2.72 \%$ \\
\hline Camphene & $1.47 \%$ \\
\hline B-Phellandrene & $0.47 \%$ \\
\hline B-Myrcene & $6.70 \%$ \\
\hline B-trans-Ocimene & $6.03 \%$ \\
\hline Linalool & $0.52 \%$ \\
\hline (ñ)-Limonene & $3.5 \%$ \\
\hline Citronellal & $11.35 \%$ \\
\hline Citronellol & $3.22 \%$ \\
\hline Z-Citral /cis-Citral & $12.49 \%$ \\
\hline cis-Geraniol & $2.08 \%$ \\
\hline Geranyl acetate & $3.82 \%$ \\
\hline Geraniol & $0.08 \%$ \\
\hline \multicolumn{2}{|l|}{ Diterpenes } \\
\hline Geranyl linalool isomer & $0.11 \%$ \\
\hline Geranyl geraniol & $0.18 \%$ \\
\hline \multicolumn{2}{|l|}{ Sesquiterpenes } \\
\hline B-Caryophyllene & $1.55 \%$ \\
\hline a-Humulene & $0.72 \%$ \\
\hline a-Muurolene & $0.53 \%$ \\
\hline Caryophyllene oxide & $0.85 \%$ \\
\hline$\gamma$-Eudesmol & $0.21 \%$ \\
\hline .tau-Muurolol & $0.25 \%$ \\
\hline B-Eudesmene & $0.60 \%$ \\
\hline B-Elemene & $0.21 \%$ \\
\hline Farnesol isomer A & $0.28 \%$ \\
\hline \multicolumn{2}{|l|}{ Phenolic compounds } \\
\hline Methyleugenol & $2.04 \%$ \\
\hline Trans-methyl iso-eugenol & $1.75 \%$ \\
\hline \multicolumn{2}{|l|}{ Others } \\
\hline Tricyclene & $0.44 \%$ \\
\hline 6-methyl-5-hepten-2-one & $0.61 \%$ \\
\hline 4-Nonanone & $1.65 \%$ \\
\hline 3,5-Heptadienal,2-ethylidene-6-methyl- & $0.55 \%$ \\
\hline $\begin{array}{l}\text { Bicyclo(3.1.1)hept-2-ene,2,6-dimethyl- } \\
\text { 6-(4-methyl-3-pentenyl)- }\end{array}$ & $0.84 \%$ \\
\hline a-Amorphene & $2.43 \%$ \\
\hline Elemol (others) & $1.35 \%$ \\
\hline Neophytadiene & $0.11 \%$ \\
\hline 6,11-Dimethyl-2,6,10-dodecatrien-1-ol & $0.24 \%$ \\
\hline
\end{tabular}

were identified with B-Caryophyllene (1.55\%) as the most abundant. The other minor compounds identified from $C$. nardus essential oil were diterpenes and phenolic compounds which respectively contributed in as many as 0.29 and $3.79 \%$ to the total volatile compositions.

\section{DISCUSSION}

The essential oil from $C$. nardus exhibited antimicrobial properties towards C. albicans at all concentration ranges. This result showed that C. albicans was the most susceptible towards citronella essential oil compared to the other microbes. This condition is partly due to in its planktonic form the $C$. albicans virulence potential decreases. ${ }^{7}$ They are commonly considered as harmless commensals and are isolated from the vagina, mouth and gastrointestinal tracts. When the host-fungus interactions become unbalanced, the fungus can initiate infection and cause disease. ${ }^{8}$ C. albicans are commonly isolated from immunocompromised patients such as HIV patients. ${ }^{8}$

However, no inhibitory effects were detected by the agar well diffusion method at the concentration of 6.25 and $12.5 \%$ for S. mutans and S. sobrinus. Both of these microorganisms were shown to be associated with the pathogenesis of dental caries. ${ }^{9}$ Compared to S. sobrinus, S. mutans plays a more vital role in producing major caries associated microbial virulence factor in caries pathogenesis. ${ }^{10}$ Presence of the high-level of $S$. mutans in the oral cavity is correlated with high caries risk. ${ }^{11}$ They adhere to the tooth surface facilitated by extracellular polysaccharides and form a biofilm which then uses as a sugar substrate in the diet for bacterial metabolism producing an acidic environment which promotes demineralisation. ${ }^{12}$ They are Gram-positive bacteria and has a thick cell wall which would explain the need for a higher concentration of the essential oil to assert its effect. ${ }^{13}$

In the present study, C. nardus essential oil at the concentration of 25 and $50 \%$ showed antimicrobial activity towards all tested pathogens. The antimicrobial activities of the $C$. nardus essential oil at different concentrations were compared with $0.2 \%$ chlorhexidine which acted as the positive control. Chlorhexidine 
digluconate $(\mathrm{CHX})$ is from biguanide group and used for plaque prevention and disinfection in dentistry due to its good antimicrobial activity apart from its staining effect and increase of calculus deposits in prolonged use. ${ }^{14,15}$ Thus, these results show that $C$. nardus essential oil had antimicrobial effect properties towards the tested microorganisms when compared to chlorhexidine. These results also showed that $C$. nardus essential oil has the potential of antimicrobial agent for use in dentistry.

It is known that microorganisms have different characters in planktonic form compared to biofilm form. ${ }^{16}$ From the findings of the current experiment, there was a requirement to carry out an additional investigation on the antimicrobial properties of the essential oil with a condition which imitates the oral condition to strengthen the study. Further studies, especially cytotoxicity and genotoxicity tests, are a necessity to determine whether $C$. nardus essential oil can be used safely in the oral cavity.

The antimicrobial activity of the $C$. nardus essential oil could be due to terpenoids and phenolics compounds. Monoterpenes are the major compounds identified. The main identified monoterpene was citronellal (11.35\%), followed by z-Citral (11.34\%), B-Myrcene $(6.70 \%)$, B-Transocimene $(6.03 \%)$, geranyl acetate (3.82\%), limonene (3.50\%), and citronellol (3.22\%). A similar finding was observed from the previous study on $C$. nardus cultivated from the state of Kelantan in Malaysia. ${ }^{17}$ This present study showed that citronellal (29.6\%) was the primary compound identified. ${ }^{17}$ However, the other compounds have differed. Only six compounds identified in $C$. nardus cultivated from both areas were the same, which were citronellal, caryophyllene, citronellol, limonene, geraniol and geranyl acetate.

Interestingly, previous studies of $C$. nardus cultivated from other countries such as Brazil ${ }^{18}$, Togo ${ }^{19}$ and Benin ${ }^{3}$ also showed that citronellal was the main identified volatile compound. However, the other compounds also differ. Therefore the significant difference in the GC-MS profiles of the C. nardus essential oil collected from different locations is consistent with the fact that plants often produce different amounts of phytochemicals when grown in different geographical origins.
On the other hand, a study of $C$. nardus essential oil that obtained from the other state in Malaysia, which was Selangor, found that the age of $C$. nardus leaves influences the composition of essential oils or volatile compounds. ${ }^{20}$ They found that citronellal $(39.66 \%)$ was the main volatile compound identified from younger leaves, while geraniol $(46.10 \%)$ was the main volatile compound identified from older leaves..$^{20}$ In the current study, C. nardus that obtained from Malacca, Malaysia showed that geraniol composition was only $0.08 \%$.

In contrast, $C$. nardus cultivated from two regions in Thailand showed that geraniol was the main identified volatile compound. ${ }^{2,21}$ However, the authors did not mention the age of the $C$. nardus leaves. Thus, the differences in volatile compounds of the $C$. nardus could be attributed to the different regions, soil and age of the leaves.

After monoterpenes, sesquiterpenes were clearly the dominant constituent in the citronella oil with total percentage of $5.20 \%$. Nine sesquiterpenes were identified and B-Caryophyllene $(1.55 \%)$ was the most abundant. B-Caryophyllene was also identified in C. nardus cultivated from Thailand $d^{2,21}$ and other regions in Malaysia ${ }^{17}$ which ranged from 0.8 to $6.5 \%$. In contrast, B-caryophyllene or caryophyllene was found in trace amount $(0.1 \%)$ in $C$. nardus cultivated from Benin ${ }^{3}$ and absent in $C$. nardus cultivated from Togo ${ }^{19}$, Brazil ${ }^{18}$ and other regions in Malaysia. ${ }^{20}$

Terpenoids are well known to possess various pharmacological effects. Studies on citronellal, showed that this compound has antibacterial activities against both Grampositive (Staphylococcus aureus) and Gramnegative (Escherichia coli) bacterial. ${ }^{22}$ Antifungal activities also have shown against several species of Aspergillus, Penicillium and Eurotium. ${ }^{2}$ z-Citral, which was known to have antibacterial activity against a wide range of Gram-positive and Gram-negative bacterial. ${ }^{23}$ The other main compounds identified were B-Myrcene, limonene and citronellol. Both studies of B-Myrcene ${ }^{24}$ and limonene ${ }^{25}$ demonstrated anti-ulcer properties. B-Myrcene was also had neuroprotective effects. ${ }^{26}$ Study on the citronellol compound showed that this compound had antidiabetic and antinociceptive effects. . $^{27,28}$ 


\section{CONCLUSION}

C. nardus essential oil shows active antibacterial properties against several oral pathogens, and the percent-ages of active volatile compounds are different from other origins.

\section{ACKNOWLEDGEMENT}

The authors would like to thank Universiti Sains Malaysia for providing financial support under Short Term Grant (304/PPSG/61313196).

\section{REFERENCES}

1. Prabuseenivasan $S$, Jayakumar $M$, Ignacimuthu S. In vitro antibacterial activity of some plant essential oils. BMC Complement Alternat Med. 2006;6:39. DOI: 10.1186/1472-6882-6-39

2. Nakahara K, Alzoreky NS, Yoshihashi T, Nguyen HTT, Trakoontivakorn G. Chemical composition and antifungal activity of essential oil from Cymbopogon nardus (citronella grass). Japan Agricult Res Quarter. 2013;37(4):249-52. DOI: $10.6090 /$ jarq. 37.249

3. Kpoviessi S, Bero J, Agbani P, Gbaguidi F, Kpadonou-Kpoviessi B, Sinsin B et al. Chemical composition, cytotoxicity and in vitro antitrypanosomal and antiplasmodial activity of the essential oils of four Cymbopogon species from Benin. J Ethnopharmacol. 2014;151(1):652-9. DOI: $\quad 10.1016 / j$. jep.2013.11.027

4. Carey DE, McNamara PJ. The impact of triclosan on the spread of antibiotic resistance in the environment. Front Microbiol 2015;5:111. DOI: $10.3389 /$ fmicb. 2014.00780

5. Fejerskov 0 . Changing paradigms in concepts on dental caries: consequences for oral health care. Caries Res. 2004;38(3):182-91. DOI: $\underline{10.1159 / 000077753}$

6. Furlletti VF, Mardegan RC, Obando-Pereda GA, Anibal PC, Duarte MCT, Goncalves RB, et al. Susceptibility of Candida spp. oral isolates for azolic antifungals and amphotericin B. Braz J Oral Sci. 2008;7(25):1543-9. DOI: 10.20396/ bjos.v7i25.8642889

7. Sharifzadeh A, Khosravi AR, Ahmadian S. Chemical composition and antifungal activity of Satureja hortensis L. essentiall oil against planktonic and biofilm growth of Candida albicans isolates from buccal lesions of $\operatorname{HIV}(+)$ individuals. Microb Pathog. 2016;96:1-9. DOI: 10.1016/j.micpath.2016.04.014

8. Hamza OJ, Matee MI, Moshi MJ, Simon EN, Mugusi F, Mikx FH et al. Species distribution and in vitro antifungal susceptibility of oral yeast isolates from Tanzanian HIV-infected patients with primary and recurrent oropharyngeal candidiasis. BMC Microbiol. 2008;8(1):135. DOI: 10.1186/1471-2180-8-135

9. Yoo Sy, Park SJ, Jeong DK, Kim KW, Lim SH, Lee $\mathrm{SH}$, et al. Isolation and characterization of the mutan streptococci from the dental plaques in Koreans. J Microbiol. 2007;45(3):246-55. DOI: 10.1099/jmm.0.46609-0

10. Pitts NB, Zero D. White paper on dental caries prevention and management. FDI World Dental Federation. 2016. p. 59.

11. Singla D, Sharma A, Sachdev V, Chopra R. Distribution of Streptococcus mutans and Streptococcus sobrinus in Dental Plaque of Indian Pre-School Children Using PCR and SB-20M Agar Medium. J Clin Diagn Res 2016;10(11):ZC60-3. DOI: 10.7860/ jedr/2016/19256.8909

12. Carmona LE, Reyes N, Gonzales F. Polymerase chain reaction for detection of streptococcus mutans and streptococcus sobrinus in dental plaque of children from cartagena, Colombia. Colomb Med. 2011;42(4):430-7. DOI: $10.25100 / \mathrm{cm} . v 42 i 4.943$

13. Samaranayake LP. Essential Microbiology for Dentistry. $2^{\text {nd }}$ ed. London: Churchill Livingstone; 2006. p. 225.

14. Takenaka S, Ohsumi T, Noiri Y. Evidence-based strategy for dental biofilms: Current evidence of mouthwashes on dental biofilm and gingivitis. Jpn Dent Sci Rev. 2019;55(1):33-40. DOI: $10.1016 / j . j d s r .2018 .07 .001$

15. James $P$, Worthington HV, Parnell $C$, Harding $M$, Lamont T, Cheung A, et al. Chlorhexidine mouthrinse as an adjunctive treatment for gingival health. Cochrane Database Syst Rev. 2017;2017(3):CD008676. DOI: 10.1002/14651858.CD008676.pub2

16. Kolenbrander PE, Andersen RN, Blehert DS, Egland PG, Foster JS, Palmer RJ Jr. 
Communication among Oral Bacteria. Microbiol Mol Biol Rev. 2002;66(3):486-505. DOI: $10.1128 / \mathrm{mmbr}$.66.3.486-505.2002

17. Wei LS, Wee W. Chemical composition and antimicrobial activity of Cymbopogon nardus citronella essential oil against systemic bacteria of aquatic animals. Iranian J Microbiol. 2013;5(2):147-52.

18. Aguiar RWDS, Ootani MA, Ascencio SD, Ferreira TPS, Santos MMD, Santos GRD. Fumigant antifungal activity of Corymbia citriodora and Cymbopogon nardus essential oils and citronellal against three fungal species. ScientificWorldJournal. 2014;2014:492138. DOI: $10.1155 / 2014 / 492138$

19. Koba K, Sanda K, Guyon C, Raynaud C, Chaumont J-P, Nicod L. In vitro cytotoxic activity of Cymbopogon citratus L. and Cymbopogon nardus L. essential oils from Togo. Bangladesh J Pharmacol. 2008;4(1):2934. DOI: $10.3329 /$ bjp.v4i1.1040

20. Weng DCJ, Latip J, Hasbullah SA, Sastrohamidjojo H. Optimal extraction and evaluation on the oil content of citronella oil extracted from Cymbopogon nardus. Malay J Analytic Sci. 2015;19(1):71-6.

21. Jumepaeng $T$, Prachakool $S$, Luthria DL, Chanthai S. Determination of antioxidant capacity and a-amylase inhibitory activity of the essential oils from citronella grass and lemongrass. Int Food Res J. 2013;20(1):133741.

22. Lopez-Romero JC, González-Rios H, Borges A, Simoes M. Antibacterial effects and mode of action of selected essential oils components against Escherichia coli and Staphylococcus aureus. Evid Based Complement Alternat Med. 2015;2015:795435. DOI: 10.1155/2015/795435

23. Vimal M, Vijaya PP, Mumtaj PP, Farhath MSS. Antibacterial activity of selected compounds of essential oils from indigenous plants. J Chem Pharm Res. 2013;5(1):248-53.

24. Bonamin F, Moraes TM, Dos Santos RC, Kushima H, Faria FM, Silva MA, et al. The effect of a minor constituent of essential oil from Citrus aurantium: The role of B-myrcene in preventing peptic ulcer disease. Chem Biol Interact. 2014;212:11-9. DOI: 10.1016/j. cbi.2014.01.009

25. Rozza AL, Moraes Tde $M$, Kushima $H$, Tanimoto A, Marques MO, Bauab TM, et al. Gastroprotective mechanisms of Citrus lemon (Rutaceae) essential oil and its majority compounds limonene and B-pinene: Involvement of heat-shock protein-70, vasoactive intestinal peptide, glutathione, sulfhydryl compounds, nitric oxide and prostaglandin E2. Chem Biol Interact. 2011;189(1-2):82-9. DOI: $10.1016 / j$. cbi.2010.09.031

26. Ciftci O, Oztanir MN, Cetin A. Neuroprotective effects of B-myrcene following global cerebral ischemia/reperfusion-mediated oxidative and neuronal damage in a C57BL/J6 mouse. Neurochem Res. 2014;39(9):1717-23. DOI: 10.1007/s11064-014-1365-4

27. Srinivasan S, Muruganathan U. Antidiabetic efficacy of citronellol, a citrus monoterpene by ameliorating the hepatic key enzymes of carbohydrate metabolism in streptozotocininduced diabetic rats. Chem Biol Interact. 2016;250:38-46. DOI: 10.1016/j. cbi.2016.02.020

28. Brito RG, Santos PL, Prado DS, Santana MT, Araújo AA, Bonjardim LR, et al. Citronellol reduces orofacial nociceptive behaviour in mice-evidence of involvement of retrosplenial cortex and periaqueductal grey areas. Basic Clin Pharmacol Toxicol. 2013;112(4):215-21. DOI: $10.1111 /$ bcpt.12018 